\title{
Superficial Bladder Carcinoma
}

National Cancer Institute

\section{Source}

National Cancer Institute. Superficial Bladder Carcinoma. NCI Thesaurus. Code C27474.

A term used by urologists to describe an infiltrating carcinoma of the bladder that has

not invaded into the muscularis propria of the bladder wall regardless of histologic type or grade. 